\title{
Clinical features of cystic fibrosis patients with
}

\section{rare genotypes}

\author{
G Castaldo, E Rippa, V Raia, D Salvatore, C Massa, G de Ritis, F Salvatore
}

\begin{abstract}
We describe the clinical features of seven cystic fibrosis patients from southern Italy who bear rare genotypes: (1) a patient homozygous for the $2183 \mathrm{AA} \rightarrow \mathrm{G}$ mutation who was affected by a very early pulmonary form of cystic fibrosis, and five patients who were compound heterozygotes either for the $2183 \mathrm{AA} \rightarrow \mathrm{G}$ mutation or for the I148T mutation, in both instances with the $\Delta$ F508 mutation; and (2) a patient homozygous for the early nonsense R553X mutation who showed only a moderately severe form of cystic fibrosis. Our results confirm that environmental or genetic factors unrelated to the CF disease contribute significantly to the development of the phenotype. ( $f$ Med Genet 1996;33:73-76)
\end{abstract}

Key words: cystic fibrosis; R553X mutation; 2183 $\mathrm{AA} \rightarrow \mathrm{G}$ mutation; I148T mutation.

In cystic fibrosis $(\mathrm{CF})$ patients from southern Italy the $\Delta \mathrm{F} 508$ microdeletion has a frequency of about $50 \%{ }^{1}$ versus 70 to $80 \%$ reported for CF patients from northern Europe. ${ }^{2}$ Therefore, while the molecular diagnosis of CF in our area is more difficult and cumbersome, our population represents a rich source of cases bearing unusual CF genotypes. The study of the correlation between these rare genotypes, particularly in the homozygous state, and the clinical expression of the disease will greatly contribute to the elucidation of the genotypephenotype correlation in CF patients.

We are now analysing all the known $\mathrm{CF}$ patients from the Campania and Lucania regions (southern Italy) using a semi-automated allele specific oligonucleotide (ASO) dot blot procedure. ${ }^{3}$ With this method we identified a panel of the most frequent CF mutations in our geographical area. ${ }^{4}$ During this screening, several CF patients with rare genotypes came to light. Here we report the clinical findings of CF compound heterozygotes for the I148T/ $\Delta F 508$ mutations and heterozygotes or homozygotes for the $2183 \mathrm{AA} \rightarrow \mathrm{G}$ mutation..$^{5-7}$ In addition, we describe the phenotype of a $\mathrm{CF}$ patient homozygous for the R553X mutation which, to our knowledge, is the third such case published.

Divisione di Pediatria, Ospedale di Villa d'Agri, Potenza, Italy D Salvatore

Correspondence to: Professor F Salvatore.

Received 6 June 1995 Revised version accepted for publication 4 September 1995
The CF mutations were analysed with a semiautomated allele specific oligonucleotide (ASO) dot blot procedure using the Biomek 1000 workstation (Beckman), which is based on two previously described multiplex PCR amplifications of the CF gene $^{3}$ at 11 DNA segments (eight exon and three intron segments). Subsequent studies, in which the analytical panel included the $2183 \mathrm{AA} \rightarrow \mathrm{G}$ mutation detected by ASO, showed the method was highly reproducible. ${ }^{4}$ The extragenic XV2c and KM19 polymorphisms were analysed with the TaqI and PstI restriction enzymes. ${ }^{89}$ For both the analyses, allele 1 corresponds to the absence of the restriction site and allele 2 to its presence. The intron $8 \mathrm{VNDR}$ was analysed by a polymerase chain reaction (PCR) amplification followed by polyacrylamide electrophoresis. ${ }^{10}$ The haplotype numbering corresponds to the number of repeats.

For each patient, the present age, the age at diagnosis, the sweat test for chloride and sodium, meconium ileus, diabetes, and nasal polyposis were recorded. The pulmonary evaluation was based on the physical examination of the patients and on the chest $x$ ray evaluation of the Chrispin-Norman score. In addition, for patients over 6 years old the forced vital capacity (FVC) and the forced expiratory volume in one second (FEV1) were measured and expressed as a percentage of the predicted normal value for sex and height. Finally, the age at lung colonisation by Pseudomonas aeruginosa was also recorded. The pancreatic evaluation was based on physical examination of the patients, fat balance, and steatocrit. Finally, liver involvement was evaluated on the basis of the physical examination, ultrasound scanning, and clinical biochemistry (aspartate aminotransferase, alanine aminotransferase, alkaline phosphatase, $\gamma$-glutamyltransferase, albumin, and Quick).

\section{Case reports}

The clinical features of the seven patients described below are listed in the table.

\section{I148T COMPOUND HETEROZYGOTES}

Two unrelated CF patients, compound heterozygotes for the $I 148 \mathrm{~T} / \Delta \mathrm{F} 508$ mutations (figure, panel A), were analysed. One patient, a female, was diagnosed at the age of 3 months on account of failure to thrive, recurrent bronchiolitis, and chronic diarrhoea. She was pancreatic insufficient and her sputum was colonised by Pseudomonas aeruginosa since she was 7 years old. The course of the disease was characterised by mild intestinal problems, normal growth, absence of diabetes and hepatopathy, and severe pulmonary involvement (FEV1 $=37 \%$ of predicted at 10 years), with 
Clinical features of the seven cystic fibrosis patients described

\begin{tabular}{|c|c|c|c|c|c|c|c|}
\hline & 1 & 2 & 3 & 4 & 5 & 6 & 7 \\
\hline Sex & $M$ & $M$ & $\mathrm{~F}$ & $\mathrm{~F}$ & $\mathrm{~F}$ & $\mathrm{~F}$ & M \\
\hline Present age & 8 & 4 & died $(16 y)$ & 4 & 2 & 4 & 21 \\
\hline Age at diagnosis & $3 \mathrm{mth}$ & $6 \mathrm{mth}$ & $3 \mathrm{mth}$ & $1 \mathrm{mth}$ & $6 \mathrm{mth}$ & $1 \mathrm{y}$ & $2 \mathrm{y}$ \\
\hline Sweat chloride* $(\mathrm{mEq} / \mathrm{l})$ & 93 & 93 & 98 & 96 & 101 & 117 & 90 \\
\hline Sweat sodium* $(\mathrm{mEq} / \mathrm{l})$ & 67 & 70 & 75 & 64 & 76 & 103 & 115 \\
\hline Meconium ileus & No & No & No & No & No & No & No \\
\hline Diabetes & No & No & No & No & No & No & No \\
\hline Nasal polyposis & No & No & No & No & No & No & Yes \\
\hline Liver involvement & No & No & No & No & No & No & No \\
\hline \multicolumn{8}{|l|}{ Age of colonisation by } \\
\hline P aeruginosa & No & No & $7 y$ & $2 \mathrm{mth}$ & $6 \mathrm{mth}$ & No & $7 y$ \\
\hline Respiratory insufficiency & No & No & Yes & No & No & No & No \\
\hline Chrispin-Norman score & 9 & $7 \cdot 5$ & 23 & 7 & 5 & 7 & 8 \\
\hline Pancreatic insufficiency & Yes & Yes & Yes & Yes & Yes & Yes & Yes \\
\hline \multirow[t]{2}{*}{ Genotype } & R553X & $\Delta \mathrm{F} 508$ & $\Delta \mathrm{F} 508$ & $2183 \mathrm{AA} \rightarrow \mathrm{G}$ & $\Delta \mathrm{F} 508$ & $\Delta \mathrm{F} 508$ & $\Delta \mathrm{F} 508$ \\
\hline & R553X & $\mathrm{I} 148 \mathrm{~T}$ & $\mathrm{I} 148 \mathrm{~T}$ & $2183 \mathrm{AA} \rightarrow \mathrm{G}$ & $2183 \mathrm{AA} \rightarrow \mathrm{G}$ & $2183 \mathrm{AA} \rightarrow \mathrm{G}$ & $2183 \mathrm{AA} \rightarrow \mathrm{G}$ \\
\hline
\end{tabular}

* Cut-off $=60 \mathrm{mEq} / \mathrm{l}$ for both sweat chloride and sodium

massive haemoptysis since the age of 15 years; the patient died at the age of 16 years.

The other case is a 4 year old boy, diagnosed at the age of 6 months on the basis of chronic diarrhoea, recurrent purulent nasal discharge, and one episode of dehydration with hypochloraemic alkalosis during the summer. $\mathrm{He}$ is pancreatic insufficient, steatorrhoea is well controlled with pancreatic extracts, and he has a very good nutritional status. Neither significant
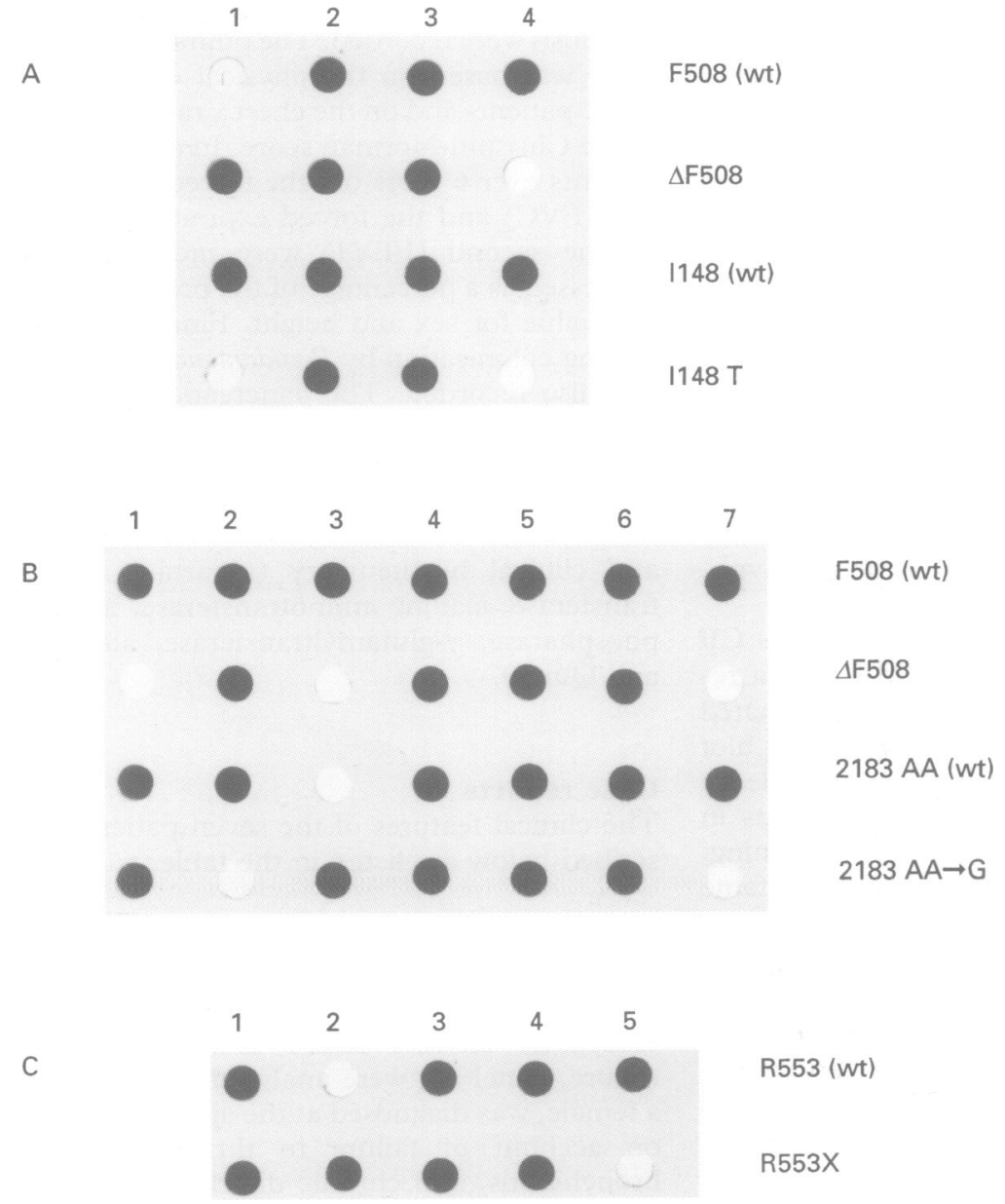

Allele specific oligonucleotide dot blot analysis of CF mutations: Panel A: $1=$ positive homozygous control for the $\triangle F 508$ mutation; 2 and $3=$ compound heterozygotes for

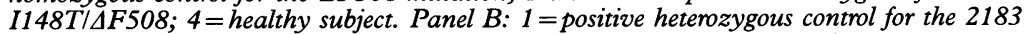
$A A \rightarrow G$ mutation; $2=$ positive heterozygous control for the $\Delta F 508$ mutation; $3=$ $A A \rightarrow G$ mutation; $2=$ positive heterozygous control for the $\triangle F 508$ mutation; $3=$
homozygote for $2183 A A \rightarrow G$ mutation; 4 to $6=$ three compound heterozygotes for 2183 $A A \rightarrow G / \Delta F 508 ; 7=$ healthy subject. Panel $C: 1=$ positive heterozygous control for $R 553 X ; 2=$ homozygous R553X CF patient; 3 and $4=$ father and mother of 2 , both heterozygous for $R 553 X ; 5=$ healthy subject. pulmonary complications nor sputum colonisation has occurred. The XV2c and KM19 haplotypes were 1,1 and 2,2, respectively, and the intron $8 \mathrm{VNDR}$ pattern was 23,23 for both cases. In our series of $246 \mathrm{CF}$ chromosomes from our region, the frequency of the I148T mutation is $0.8 \%$ (unpublished results).

\section{$2183 \mathrm{AA} \rightarrow \mathrm{G}$ HOMOZYGOTES AND}

\section{HETEROZYGOTES}

We studied four unrelated CF patients bearing the $2183 \mathrm{AA} \rightarrow \mathrm{G}$ mutation, one homozygote and three compound heterozygotes with $\Delta \mathrm{F} 508$ (figure, panel B). The homozygous patient is a 4 year old girl diagnosed at the age of 1 month on account of failure to thrive, steatorrhoea, and respiratory distress with atelectasia of the right upper pulmonary lobe and $P$ aeruginosa in pharyngeal aspirate cultures. She improved with pancreatic enzyme supplementation and, at present, has a good nutritional status and moderate pulmonary symptoms; her sputum is colonised by $P$ aeruginosa in spite of early, intensive, antibiotic therapy.

The heterozygous patients are one male of 21 years and two females of 4 and 2 years. They were diagnosed at the ages of 2 years, 1 year, and 6 months, respectively, on account of failure to thrive with chronic diarrhoea, steatorrhoea, and recurrent respiratory symptoms. The 21 year old male patient, who is pancreatic insufficient, has sputum colonised by $P$ aeruginosa (since the age of 7 years) and was surgically treated three times for nasal polyposis. He has never had diabetic or hepatic complications and was affected by mild pneumonopathy until the age of 17 years (FEV1 $82 \%$ of predicted); pulmonary involvement has increased in the last three years causing a decline in pulmonary function and the FEV1 is now $49 \%$ of predicted.

The two girls show pancreatic insufficiency. Lung involvement was early with atelectasia of the right medium lobe in one patient and early presence of $P$ aeruginosa in sputum culture in the other. Both these problems were successfully treated with antibiotics and chest physiotherapy and, at present, the two patients have only mild respiratory symptoms.

In all four cases, the $2183 \mathrm{AA} \rightarrow \mathrm{G}$ mutation is associated with alleles 1 and 2 (XV2c and 
KM19, respectively) and with allele 23 (intron 8 VNDR). The incidence of the $2183 \mathrm{AA} \rightarrow \mathrm{G}$ mutation in our sample of $246 \mathrm{CF}$ chromosomes is $2.0 \%$ (unpublished results).

\section{R553X HOMOZYGOTE}

This male was diagnosed as suffering from $\mathrm{CF}$ at the age of 3 months on the basis of failure to thrive, diarrhoea, and sweat test. $\mathrm{He}$ is the only child of healthy parents (third degree relatives) from Campania (southern Italy). At present, at the age of 8 years, he has mild pulmonary involvement (FEV1 86\% and FVC $76 \%$ ), with sporadic presence of $P$ aeruginosa in the sputum. Neither meconium ileus nor diabetes was present. From the steatocrit and clinical course, the patient was defined as pancreatic insufficient with a poor response to pancreatic enzyme supplementation indicated by failure to thrive and steatorrhoea. The physical examination (mild hepatomegaly), clinical biochemistry (AST, ALT, AP, and GGT increased less than twice the upper limit), and ultrasound scanning (dyshomogeneity of the parenchyma) indicated mild hepatic involvement.

The R553X mutation (figure, panel C) is associated with alleles 1,1 for the XV2c and KM19 polymorphisms and with allele 16 (intron 8 VNDR). The incidence of the R553X mutation in our population of $246 \mathrm{CF}$ chromosomes is $1.2 \%$ (unpublished results).

\section{Discussion}

The cloning of the cystic fibrosis transmembrane regulator (CFTR) gene and the characterisation of the molecular defects have resulted in numerous studies on genotypephenotype correlations, and on the relationship between specific mutations and the clinical heterogeneity of the disease. ${ }^{11-13}$

The I148T mutation has been identified in $0.2 \%$ of Canadian patients ${ }^{6}$ and in $0.08 \%$ of French patients ${ }^{7}$; the latter study gives an incidence of $0.9 \%$ for the $2183 \mathrm{AA} \rightarrow \mathrm{G}$ mutation and in a recent paper on $\mathrm{CF}$ patients from northern Italy the incidence of the $2183 \mathrm{AA} \rightarrow \mathrm{G}$ mutation was $9 \cdot 33 \% .{ }^{14}$ These figures compare with an incidence of $0.8 \%$ for I148T and of $2.0 \%$ for $2183 \mathrm{AA} \rightarrow \mathrm{G}$ in our region.

All I148T and $2183 \mathrm{AA} \rightarrow \mathrm{G} \mathrm{CF}$ cases described here presented with pancreatic insufficiency. All our patients also showed various degrees of pulmonary involvement, but no conclusion can be drawn as to the severity of lung disease and the presence of $\Delta \mathrm{F} 508, \mathrm{I} 148 \mathrm{~T}$, and $2183 \mathrm{AA} \rightarrow \mathrm{G}$ genotypes, because most of our patients are still very young and no comparable published data are available. Thus, we are unable to contribute to the debate ${ }^{11-13}$ about the correlation between genotype and lung involvement. The early expression of pneumonopathy in the patient homozygous for 2183 $A A \rightarrow G$ and in two of the three compound heterozygous cases for the same mutation, together with the early colonisation of the sputum by $P$ aeruginosa, which is very unusual in preschool children, suggests a poor prognosis for lung involvement in these patients. Our results agree with those obtained in three CF patients homozygous for the $2183 \mathrm{AA} \rightarrow \mathrm{G}$ mutation. ${ }^{14}$ All the cases with $\mathrm{I} 148 \mathrm{~T}$ and $2183 \mathrm{AA} \rightarrow \mathrm{G}$ were diagnosed within the first year of life, which is indicative of the severity of these mutations. This severity coincides with the "frameshift" nature of the mutations.

The two previously reported cases homozygous for R553X are heterogeneous, one being characterised by a moderate-severe form of the disease with lung and pancreas involvement, ${ }^{15}$ the other by very mild pulmonary involvement. ${ }^{16}$ Our patient showed mild pulmonary involvement and pancreatic insufficiency and hence shows an intermediate phenotype. The rare haplotype associated with this homozygous $\mathrm{R} 553 \mathrm{X}$ patient $(1,1$ for both the XV2c and KM19 polymorphisms, and 16, 16 for the intron 8 VNDR) was also detected in one of the two homozygous R553X cases described, ${ }^{16}$ the other case being heterozygous for both the XV2c and KM19 markers. ${ }^{15}$ These observations support the hypothesis that the R553X mutation occurred more than once during evolution, as has also been described for the R117H mutation. ${ }^{17}$

Thus, the three homozygous R553X cases appear to be associated with a moderate form of cystic fibrosis, with a phenotype less severe than that usually found in $\Delta \mathrm{F} 508$ homozygous patients, which is surprising because $\mathrm{R} 553 \mathrm{X}$ is a nonsense mutation. As previously suggested, ${ }^{16}$ the complete absence of CFTR production could be better tolerated by cells and tissues than the production of a mutated protein, even if the R553X mutation results in a very low percentage of wild type transcripts. ${ }^{1819}$

In conclusion, the three cases bearing the $2183 \mathrm{AA} \rightarrow \mathrm{G}$ mutation exhibit early pulmonary expression of the disease, and this feature is more evident in the $2183 \mathrm{AA} \rightarrow \mathrm{G}$ homozygous patient. The R553X mutation in the homozygous form seems to express a moderate CF phenotype analogous to one of the two previously described cases homozygous for the R553X mutation. Finally, the two patients bearing the I148T mutation were heterogeneous for both clinical features and age; however, given the lack of previous reports of this type, other case reports are required in order to establish a genotype/phenotype correlation.

The results reported in this study also support the view that environmental factors, in addition to genetic factors, are related to the clinical heterogeneity of CF patients.

Grants from MURST, Regione Campania, AGENSUD, CNR (PF Biotecnologie e Biostrumentazioni e PF Ingegneria Genetica) are gratefully acknowledged.

1 Santamaria F, Salvatore D, Castaglione O, Raia V, De Ritis $G$, Sebastio $G$. Lung involvement, the $\Delta F 508$ mutation and DNA haplotype analysis in cystic fibrosis. Hum Genet 1992;88:639-41.

2 Romeo G, Devoto M. Population analysis of the major mutation in cystic fibrosis. Hum Genet 1992;85:391-445.

De Marchi JM, Richards CS, Fenwick RG, Pace R, Beaude AL. A robotics-assisted procedure for large scale cystic fibrosis mutation analysis. Hum Mutat 1994;4:281-90.

4 Castaldo G, Salvatore F, Sebastio G, et al. Analysis of 22 mutations and of the XV2c and KM19 polymorphisms in 132 chromosomes of cystic fibrosis patients from the Naples (Italy) area. F Tumor Marker Oncol 1994;9:71.

5 Bozon D, Zielinski J, Rininsland F, et al. Identification of four new mutations in the cystic fibrosis transmembrane 
conductance regulator (CFTR) gene: $1148 \mathrm{~T}, \mathrm{~L} 1077 \mathrm{P}$, $\mathrm{Y} 1092 \mathrm{X}, 2183 \mathrm{AA} \rightarrow \mathrm{G}$. Hum Mutat 1994;3:330-4

6 Kristidis P, Bozon D, Corey M, et al. Genetic determination of pancreatic function in cystic fibrosis. Am $\mathcal{F}$ Hum Genet 1993;50:1178-84

7 Chevalier-Porst F, Bonardot AM, Gilly R, et al. Mutation analysis in 600 French cystic fibrosis patients. $\mathcal{f} \mathrm{Med}$ Genet 1994;31:541-4.

8 Rosenbloom CL, Kerem BS, Rommens JM, et al. DNA amplification for detection of the XV 2c polymorphism linked to cystic fibrosis. Nucleic Acids Res 1989;17:7117.

9 Feldman GL, Williamson R, Beaudet AL, O'Brien WE. Prenatal diagnosis of cystic fibrosis by DNA amplification for detection of KM 19 polymorphism. Lancet 1988;i: 102 .

10 Morral N, Nunes V, Casals T, Estivill X. CA/GT microsatellite alleles within the cystic fibrosis transmembrane conductance regulator (CFTR) gene are not generated by unequal crossingover. Genomics 1991;10:692-8.

11 Kerem E, Corey M, Kerem BS, et al. The relation between genotype and phenotype in cystic fibrosis: analysis of the most common mutation. N Engl F Med 1990;323:1517-22.

12 The Cystic Fibrosis Genotype-Phenotype Consortium. Correlation between genotype and phenotype in patients with cystic fibrosis. N Engl f Med 1993;329:1308-13.
13 Dean M, Santis G. Heterogeneity in the severity of cystic fibrosis and the role of CFTR gene mutations. Hum Genet 1994;93:364-8.

14 Bonizzato A, Bisceglia L, Marigo C, et al. Analysis of the complete coding region of the CFTR gene in a cohort of CF patients from North Eastern Italy: identification of 90\% of the mutations. Hum Genet 1995;95:397-402.

15 Cheadle J, Al-Jader L, Goodchild M, Meredith AL. Mild pulmonary disease in a cystic fibrosis child homozygous for R553X. F Med Genet 1992;29:597. 16 Bal J, Stuhrmann M, Schloesser M, Schmidtke J, Reiss J. mutation R553X. 7 Med Genet 1991;28:715-17.

17 Reiss J, Cooper DN, Bal J, et al. Discrimination between recurrent mutation and identity by descent: application to point mutations in exon 11 of the cystic fibrosis (CFTR) gene. Hum Genet 1991;87:457-61.

18 Hamosh A, Trapnell BC, Zeitlin PL, et al. Severe deficiency of cystic fibrosis transmembrane conductance regulator messenger RNA carrying nonsense mutations R553X and W1316X in respiratory epithelial cells of patients with W1316X in respiratory epithelial cells of patie

19 Will K, Reiss J, Dean M, et al. CFTR transcripts are undetectable in lymphocytes and respiratory epithelial cells of a CF patient homozygous for the nonsense mutation R553X. $\mathcal{f}$ Med Genet 1993;30:833-7. 